\title{
Acenos sobre a história da psicologia moderna e o desenvolvimento da Ontopsicologia
}

\author{
Fernando Duarte Martins de Oliveira
}

Resumo: Este trabalho, realizado a partir de revisão bibliográfica, apresenta um breve resgate histórico sobre a trajetória da psicologia e o nascimento da Ontopsicologia apontando os principais elementos (na visão do autor) que contribuíram para que a psicologia dos séculos XIX e XX se desviasse, dentro da pesquisa acerca do homem, dos pontos fundamentais que possibilitariam o encontro de uma resposta aos questionamentos da subjetividade humana. Após um breve aceno sobre o surgimento da Ontopsicologia e suas três principais descobertas, são apresentadas as contribuições referentes à definição, especificação e acréscimo científico e objetivo àquilo que vislumbrou a psicologia humanista apontando ainda para como a Ontopsicologia traz solução ao problema crítico do conhecimento.

Palavras-chave: Psicologia; Ontopsicologia; Behaviorismo; Psicanálise; Psicologia Humanista.

Briefing about the history of modern psychology and the development of Ontopsychology

Abstract: This work, based on a bibliographical review, presents a brief historical review of the trajectory of psychology and the birth of Ontopsychology and also points out the main elements (in the author's view) that contributed to the psychology of the XIX and XX centuries, Within the research about man, of the fundamental points that would enable the finding of an answer to the questions of human subjectivity. After a brief nod on the emergence of Ontopsychology and its three main discoveries, the contributions that it makes with regard to the definition, specification and scientific and objective addition to what was glimpsed by the humanistic psychology are presented, and also points out how Ontopsychology brings a solution to the critical problem of knowledge.

Keywords: Psychology; Ontopsychology; Behaviorism; Psychoanalysis; Humanistic Psychology

Exposiciones sobre la historia de la psicología moderna y el desarrollo de la Ontopsicología

Resumen: Este trabajo, realizado a partir de revisión bibliográfica, presenta un breve rescate histórico sobre la trayectoria de la psicología y el nacimiento de la Ontopsicología, apuntando los principales elementos (en la visión del autor) que contribuyeron para que la psicología de los siglos XIX y XX se desviara, dentro de la investigación acerca del hombre, de los puntos fundamentales que posibilitarían el encuentro de una respuesta a los cuestionamientos de la subjetividad humana. Después de una breve exposición sobre el surgimiento de la Ontopsicología y sus tres principales descubrimientos, se presentan las contribuciones referentes a la definición, especificación y acrecimiento 
científico y objetivo a aquello que vislumbró la psicología humanista apuntando cómo la Ontopsicología trae solución al problema crítico del conocimiento.

Palabras clave: Psicología; Ontopsicología; conductismo; el psicoanálisis; Psicología Humanista.

\section{Introdução}

Antes de qualquer aceno acerca das correntes de pensamento que são objeto ou instrumento de nosso trabalho é necessário considerar que a compreensão da subjetividade humana é tema que perpassa muitos séculos.

"Quid est veritas?", questionou o pretor romano Pôncio Pilatos, dando notoriedade bíblica a um dos desdobramentos do tema radical de toda a pesquisa epistemológica desde os primórdios do pensamento filosófico. O homem questiona o mundo, a existência e a si mesmo em busca da "verdade" sobre a própria identidade desde os tempos antigos. Durante essa jornada de pesquisa, ao transcorrer dos séculos XIX e XX, a humanidade observa o desenvolver-se e formalizar-se da "Psicologia", ciência que toma para si uma investigação até então abordada pela filosofia. De acordo com o que afirma Schultz,

[...] já no século V a.C., quando Platão, Aristóteles e outros filósofos gregos já discutiam muitas questões comuns aos psicólogos de hoje. Entre essas ideias estão alguns dos tópicos básicos abordados nos cursos de psicologia: memória, aprendizagem, motivação, pensamento, percepção, comportamento anormal.[...] Desse modo, um início possível para o estudo da história da psicologia poderia nos levar aos antigos textos filosóficos sobre problemas que mais tarde foram incluídos na disciplina formalmente conhecida como psicologia (SCHULTZ; SCHULTZ, 2014, p. 3-4).

No ritmo das vultosas descobertas realizadas dentro das ciências naturais, do modelo positivista e fortemente embasada no crescimento da fisiologia como ciência, durante o século XIX a Psicologia desenvolve suas ferramentas de pesquisa e sua visão de homem, amplamente voltadas à tendência positivista da época,

\footnotetext{
1 "O que é a verdade?” trad. do Latim.
} 


\begin{abstract}
Em meados do século XIX, os métodos das ciências naturais estavam sendo empregados para pesquisar fenômenos puramente mentais. Técnicas foram desenvolvidas, aparelhagens foram criadas, livros importantes foram escritos e o interesse crescente se espalhava. Os astrônomos e filósofos empiristas britânicos enfatizavam a importância dos sentidos, e os cientistas alemães descreviam o seu funcionamento. O espírito intelectual positivista da época, o Zeitgeist ${ }^{2}$, incentivava a convergência dessas duas linhas de pensamento (SCHULTZ; SCHULTZ, 2014, p. 63).
\end{abstract}

Ainda segundo Schultz (2014), Wilhelm Wundt, cientista alemão nascido em 1832 e falecido em 1920, foi o principal responsável pela unificação e fundação da psicologia experimental, inaugurando o primeiro laboratório e lançando a primeira revista especializada. A partir daí a psicologia se desenvolveu de forma autônoma, pelo trabalho de inúmeros pesquisadores e cientistas desenvolvendo suas escolas de pensamento através da crítica e oposição às ideias dos sistemas precedentes. Assim, surgiram: o estruturalismo, o funcionalismo, o behaviorismo, e mais tarde psicologia da gestalt, entre outras.

Essa contextualização se faz importante dado que, o objetivo deste trabalho é elencar as principais características da psicologia humanista (vertente de pensamento nascida no século XX e proveniente das evoluções das teorias da personalidade iniciadas a partir da psicanálise), demonstrar como ela se diferenciou das duas outras grandes forças da psicologia (a psicanálise e o behaviorismo) e apontar os elementos de avanço teórico e científico trazidos pela Ciência Ontopsicológica, que, mesmo não sendo psicologia, resolve inúmeras questões que ainda hoje são grandes incógnitas para a própria psicologia, assim como, para a ciência em geral.

\title{
2 Fundamentação Teórica
}

\subsection{Behaviorismo e Psicanálise: as duas grandes forças}

No ano de 1914 John B. Watson ${ }^{3}$ publica seu livro intitulado "Behavior: an introduction to comparative psychology" onde defende a aceitação da psicologia animal e as vantagens de usar animais em pesquisas psicológicas. O behaviorismo de Watson defendia que, para que a psicologia se tornasse ciência natural objetiva, ela deveria se livrar de toda e qualquer possibilidade de introspecção e subjetividade, seu ambiente

\footnotetext{
2 Zeitgeist, segundo Schultz e Schultz, trata-se do espírito de uma época (2014, p.9). 3 1878-1958.
} 
experimental deveria ser altamente controlado e características humanas como, "percepção", "afeição", "volição" e "emoção", por exemplo, não seriam relevantes para o estudo do comportamento, que em sua concepção é o campo de ação da psicologia. Para o behaviorismo, "estímulo-resposta" é a única relação que poderia ser considerada cientificamente nas experiências dentro da psicologia. Nas palavras de Watson:

\begin{abstract}
A psicologia, na visão do behaviorista, é um ramo puramente objetivo da ciência natural. Seu objetivo teórico é a previsão e o controle do comportamento. A introspecção não faz parte essencial dos seus métodos, nem o valor científico dos seus dados depende da prontidão com que se prestam à interpretação em razão da consciência. O behaviorista, em um esforço para obter um projeto unitário de resposta animal, reconhece não haver linha divisória entre o homem e o animal.[...]" (Trecho de "Psychology as the behaviorist views it, Psychological Review, n. 20, p. 158-177, 1913 In: SCHULTZ;SCHULTZ, 2014, p. 218).
\end{abstract}

Watson, através desse texto deixa clara qual é a visão de homem do behaviorismo, descarta qualquer traço de racionalidade ou de qualquer característica que diferencie a espécie humana das demais espécies de animais, reduzindo a complexidade do homem a um "mecanismo" de "estímulo - resposta".

Enquanto isso, no velho continente, na mesma época histórica Sigmund Freud ${ }^{4}$, um médico, nascido em Pribor, na atual República Tcheca, que havia passado a infância e a adolescência em Viena (onde também viveu a maior parte de sua vida), fez surgir a psicanálise, um método que "desenvolveu-se à margem da psicologia acadêmica geral e, assim, permaneceu durante vários anos" (SCHULTZ; SCHULTZ, 2014, p. 310). Utilizando-se do método catártico, apresentado a ele pelo médico Josef Breuer (18421925), através do relato do famoso caso de Anna O. e junto de experiências pessoais e análise de alguns casos clínicos, Freud desenvolve sua doutrina através de um prisma ignorado e negligenciado pelo meio acadêmico da psicologia da época, dando origem a um próprio sistema de personalidade. Acerca disso:

\footnotetext{
O sistema de Freud não abrangia todos os tópicos geralmente abordados nos livros básicos de psicologia da época, mas explorava áreas que outros psicólogos tendiam a ignorar: as forças motivadoras do inconsciente, os conflitos entre essas forças e os efeitos desses conflitos no comportamento (SCHULTZ; SCHULTZ, 2014, p. 305).
}

Dessa forma, Freud postula sua primeira teoria que dá a distinção entre a visão da psicanálise e a psicologia da época:

\footnotetext{
4 1856-1939.
} 
Em 1900, no livro A interpretação dos sonhos, Freud apresenta a primeira concepção sobre a estrutura e o funcionamento psíquicos. Essa teoria refere-se à existência de três sistemas ou instâncias psíquicas: inconsciente, pré-consciente e consciente (BOCK, FURTADO e TEIXEIRA, 2008, p. 49).

Porém, ao longo de suas pesquisas e da evolução das concepções psicanalíticas, Freud "remodela a teoria do aparelho psíquico e introduz os conceitos de id, ego, superego para referir-se aos três sistemas de personalidade" (BOCK, FURTADO e TEIXEIRA, 2008, p. 51).

Sigmund Freud também concluiu ao longo de suas pesquisas, que a causa predominante de todas as neuroses e da repressão de certos pensamentos e desejos é sempre um conflito de ordem sexual. Essa visão acaba constituindo o ponto central de toda a psicanálise freudiana, e é nesse ponto que sua teoria entende o funcionamento da dinâmica da psique humana reduzido aos seus aspectos e motivações sexuais. Por volta de 1898, Freud disse: "as principais e mais imediatas causas, para fins práticos, do distúrbio neurótico estão nos fatores oriundos da vida sexual" (apud SCHULTZ; SCHULTZ, 2014, p. 294 apud Breger, 2000, p. 117).

\title{
2.2 Psicologia Humanista: a terceira força
}

Nas décadas de 1950 e 1960, a psicologia humanista, chamada de terceira força, se desenvolvia com notável destaque. Os trabalhos de Abraham Maslow e Carl Rogers ${ }^{6}$ representaram evoluções da teoria da personalidade, e traziam uma visão de homem completamente distinta daquela tratada pelo behaviorismo e pela psicanálise.

\begin{abstract}
A psicologia humanista enfatizava o poder do homem, bem como as suas aspirações positivas, a experiência consciente, o livre-arbítrio (não o determinismo), a plena utilização do potencial humano e a crença da integridade da natureza humana. É fácil perceber como esses temas são bem distintos daqueles abordados no behaviorismo ou na psicanálise (SCHULTZ; SCHULTZ, 2014, p. 336).
\end{abstract}

Poucas décadas antes, trabalhos como a elaboração do conceito de "psicologia individual" de Alfred Adler, a teoria do "medo a liberdade" de Erich Fromm, a escola da "psicologia analítica" de Carl Gustav Jung, entre outros, proporcionam um rompimento

\footnotetext{
5 1908-1970

6 1902-1987
} 
com a visão determinista de homem, tanto do behaviorismo (enquanto compreendia o homem como uma "máquina" de estímulo - resposta) quanto da psicanálise (no quanto reduzia o homem a um mero condicionado de seus impulsos sexuais), inaugurando uma nova forma de compreender psicologia no ser humano, buscando aspectos positivos como a "autorrealização", da qual tratará Maslow, e a "atenção positiva"8 de Rogers. Ainda mais, segundo Schultz:

Na visão de Maslow, cada indivíduo é dotado de propensão inata à autorrealização (Maslow, 1970). Esse estado, o mais elevado das necessidades humanas, envolve o uso ativo de todas as qualidades e habilidades, além do desenvolvimento e da aplicação plena do potencial individual. Para o indivíduo sentir-se autorrealizado, primeiro é necessário satisfazer as necessidades mais inferiores na hierarquia inata e cada uma delas deve ser satisfeita antes que a próxima nos motive (SCHULTZ; SCHULTZ, 2014, p. 338).

Maslow pesquisara quais características possuiria um ser humano que pudesse ser considerado psicologicamente saudável, para ele, o ser humano autorrealizado representaria esse modelo ao passo que sua vida psíquica contemplaria dimensões como:

“1. percepção objetiva da realidade;

2. plena aceitação da própria natureza;

3. compromisso e dedicação a algum tipo de trabalho;

4. simplicidade e naturalidade do comportamento;

5. necessidade de autonomia, privacidade e independência;

6. experiências de "pico" ou místicas intensas;

7. empatia e afeição pela humanidade;

8. resistência ao conformismo;

9. estrutura de caráter democrático;

10. atitude de criatividade;

11. alto grau do que Adler chamava de interesse social"

(SCHULTZ; SCHULTZ, 2014, p. 339)

Já para Rogers, “A maior força motivadora da personalidade é o impulso para a realização do self (SCHULTZ; SCHULTZ, 2014, p. 343) e ainda, durante a infância, de acordo com os tipos de experiências que a criança tivesse, a autorrealização poderia ser reprimida, e afetar assim o seu senso de self. Dentro deste contexto:

\footnotetext{
7 "Autorrealização: desenvolvimento pleno das habilidades de um indivíduo e realização de seu potencial" (SCHULTZ; SCHULTZ, 2014, p. 338)

8 “Atenção Positiva: amor incondicional da mãe pelo bebê"
} 
Rogers enfatiza a importância da relação entre mãe e filho por ela afetar o senso de self em evolução da criança. Se a mãe satisfaz a necessidade de amor do bebê, que Rogers chamou de atenção positiva, ele provavelmente terá uma personalidade saudável (SCHULTZ; SCHULTZ, 2014, p. 343).

Assim como Maslow, Rogers também acreditava ser a autorrealização o pleno indicador da saúde psicológica, porém o seu fator determinante seria o proceder da mãe durante a infância do indivíduo. O desenvolvimento da saúde psicológica estava atrelado à atenção positiva, e para que o indivíduo se realizasse no futuro, a atuação da atenção positiva na infância era determinante. Para Rogers, a pessoa dotada de saúde psicológica plena apresenta as seguintes tendências:

- “mente aberta para aceitar qualquer tipo de experiência e de novidades;

- tendência a viver plenamente cada momento;

- capacidade para se orientar pelos próprios instintos e não pelas opiniões ou razões de outras pessoas;

- $\quad$ senso de liberdade no pensamento e na ação;

- alto grau de criatividade;

- necessidade contínua de maximizar o seu potencial” (SCHULTZ; SCHULTZ, 2014, p. 344)

Carl Rogers e Abraham Maslow não foram os únicos expoentes da psicologia humanista, porém suas visões acerca do humano deixam claro o início de uma nova proposição acerca do que é o homem.

Observa-se no transcorrer da pesquisa psicológica, desde Wundt até Rogers, uma evolução nas tentativas de compreender e definir, objetivamente, o ser humano. Porém, jamais houve consenso em relação ao critério que dá identidade ao homem. $O$ que é $o$ homem? A psicologia assume para si uma pesquisa originalmente filosófica e, ao longo de sua trajetória, gradualmente se afasta das problemáticas que deram origem a essa mesma pesquisa. A terceira força inicia um olhar amplo sobre as características positivas do homem, mas ainda não é capaz de defini-las, observá-las e estudá-las cientificamente, falta ainda um critério. É nesse contexto que, em 1956 reúnem-se em Paris alguns expoentes da psicologia da época, entre os quais Carl Rogers, Rollo May, Abraham Maslow, Anthony Sutich e outros (Meneghetti, 2010), dessa conferência, realizada com fundos próprios, sem 
qualquer apoio institucional, surge uma concepção que Maslow comenta no prefácio da segunda edição do seu escrito "Introdução à psicologia do ser", como afirma Meneghetti:

(...) a Psicologia humanista era apenas um momento de transição. 'Um prólogo a uma quarta psicologia ainda mais elevada, transpessoal, transumana, centrada mais no cosmo que nas necessidades e no interesse humano', uma força que devia ir além dos conceitos de humanidade, identidade e autorrealização. Além disso, acrescentava Maslow, o existencialismo podia constituir um ulterior impulso rumo ao desenvolvimento de outro ramo da psicologia: a psicologia do self completamente desenvolvido e autêntico, e dos modos de ser. Sutich sugeriu o nome Ontopsicologia (MENEGHETTI, 2010, p. 98).

Nesse sentido, abre-se a possibilidade de uma nova abordagem psicológica. A Ontopsicologia responderá a este apelo, entretanto, não enquanto uma abordagem psicológica, mas como uma nova teoria do conhecimento, reunindo em si uma interdisciplinaridade que lhe é inerente ao apresentar uma antropologia pautada no critério ôntico, como será possível notar a seguir.

\subsection{Ontopsicologia: a revelação do fundamento ontológico do humano}

O termo "Ontopsicologia", já havia surgido, mas faltava o cientista apto a formalizá-la, faltava "a mente que pudesse indicar claramente este novo percurso. Os grandes da psicologia de então não sabiam como deveria ser esta Ontopsicologia, ou melhor, a psicologia que revela o fundamento ontológico do humano" (Meneghetti 2010,p. 98). Assim, com Antonio Meneghetti ${ }^{9}$ : a Ontopsicologia ganha um corpo estrutural, teórico, científico:

(...) é inaugurado em Roma, em 15 de novembro de 1972, um Centro de Terapia Ontopsicológica autônomo. O Centro oferece imediatamente cursos com diferentes durações (até um máximo de três anos), de formação em psicoterapia ontopsicológica. Dos resultados positivos obtidos no campo da cura, o Prof. Meneghetti recolhe elementos que lhe permitem chegar a uma série de descobertas que serão gradualmente expostas nas convenções de Ontopsicologia, organizadas a partir de 1973, justamente com o escopo de expor os resultados clínicos, que sucessivamente são formalizados através de publicações (MENEGHETTI, 2010, p.100).

\footnotetext{
91936 - 2013. “Acadêmico Prof. Antonio Meneghetti, possui Doutorado clássico em Teologia junto a Pontifícia Universidade Lateraense em Roma, Doutorado clássico em Filosofia e Doutorado clássico em Ciências Sociais pela Pontifícia Universidade São Tomás de Aquino. Láurea em Filosofia com abordagem psicológica na Universidade Católica Sacro Cuore em Milão. Gran Doctor Nauk em Ciências Psicológicas concedido pela Suprema Corte de Avaliação Interministerial da Federação Russa" (MENEGHETTI, 2010, p.15).
} 
As descobertas realizadas por Antonio Meneghetti possibilitam a ele isolar, identificar e descrever o critério fundamental do humano, e a partir deste critério, formalizar e operar uma ciência que se apresenta como solução ao problema crítico do conhecimento. Durante seu percurso de prática clínica, realiza a primeira descoberta, o Campo Semântico.

Trata-se do espaço de informação de signos energéticos, ou seja, um "campo semântico" onde é possível compreender as energias formalizadas, as informações, presentes no sujeito a um nível inconsciente que o mesmo desconhece conscientemente. As informações do campo semântico formalizam o real do sujeito.

A compreensão do campo semântico e a sua utilização como ferramenta dentro da análise clínica, possibilitou ao Acadêmico Professor Antonio Meneghetti (2010) compreende e definir uma psicologia negativa afetando o sujeito em seus processos biológicos. Detendo-se uma análise até a radicalidade última desse fenômeno, deu-se a segunda descoberta, o Monitor de Deflexão, um modo de operação automática, um estabilizador obsessivo que deforma as projeções do real.

Por fim, há a descoberta do Em Si ôntico, que orienta toda a epistemologia ontopsicológica, trata-se do critério de natureza presente no ser humano, ou seja, a própria natureza do homem. Conduzir o real fenomênico do homem, sua consciência a esta informação, Em Si ôntico é a tarefa fundamental da Ontopsicologia (MENEGHETTI, 2010).

As descobertas do Campo Semântico, Monitor de Deflexão e Em Sí ôntico, trazidas pela Ontopsicologia, deram ao estudo da natureza humana em geral uma possibilidade resolutiva distinta de todas as outras que a precederam. A partir de então, tornou-se possível encontrar objetividade na subjetividade da natureza humana.

\section{Método}

No que se refere ao método, o presente trabalho foi realizado através de pesquisa e revisão bibliográfica com posterior discussão teórica.

\section{Considerações Finais}


Durante mais de cem anos, as pesquisas em psicologia seguiram diversos caminhos. É interessante observar que, apesar de ter surgido a partir da filosofia, a pesquisa psicológica, em um determinado momento, se afasta dessa origem. $\mathrm{O}$ mecanicismo positivista do século XIX começa a permear as reflexões acerca do homem, que começa a ser entendido como máquina puramente mecânica, e é nesse ponto que o homem começa a desviar-se da própria realidade. A visão cada vez mais positivista que o avanço das ditas "ciências naturais" e das "ciências exatas" fomenta, leva o homem a um comportamento generalista, baseado na pretensão de que, através do método científico cartesiano, seria capaz de encontrar a verdade através da objetividade dos fenômenos humanos. Hoje é evidente que isso não era possível, pois faltava um elemento essencial: um critério que fosse referente ao real, referente à própria natureza.

Ao se afastar do conhecimento epistêmico, filosófico-ontológico, a psicologia posterior a Wundt perde a possibilidade de encontrar um critério de medida para fazer racionalidade acerca do homem.

Antonio Meneghetti, através da formalização da Ontopsicologia, que se configura como epítome do conhecimento humano, com as suas três descobertas, devolve o fundamento ontológico da própria existência ao homem, no quanto apresenta o critério objetivo segundo o qual o homem é: o Em Sí ôntico. A Ontopsicologia traz a solução aos problemas da subjetividade humana.

Enquanto a psicologia humanista despertava a percepção de que o homem é em si um projeto aberto e não determinado ou reduzido, como inferiam a psicanálise e o behaviorismo, ela percebia também que o homem tendia à realização, à liberdade, à autonomia, à felicidade, entretanto, sendo incapaz de definir, objetivamente, como essas tensões se davam, como se manifestavam, que características tinham, onde se originavam. A terceira força, apesar de vislumbrar algo de verdadeiro do homem, carecia de objetividade científica, objetividade essa que foi aportada pela Ontopsicologia de Antonio Meneghetti.

Evidentemente, o presente trabalho não fecha o tema para futuras pesquisas, uma vez que se configura como breve aceno às questões abordadas, e portanto, abre um extenso leque ao aprofundamento da pesquisa tanto no que tange ao resgate histórico do tema quanto à Ciência Ontopsicológica (tema que preenche inúmeras obras de inestimável valor intelectual). 
Concluo que o grande acréscimo trazido pela Ciência Ontopsicológica tornou possível autenticar o homem em conformidade à própria natureza, através do seu critério epistemológico e dos métodos de intervenção ontopsicológica (assunto a ser tratado em um próximo trabalho), consentindo assim a produção de conhecimento epistêmico. Afinal, como entende a Ontopsicologia, podemos dizer que só é capaz de fazer conhecimento epistêmico aquele pesquisador que estiver em conformidade com a sua própria natureza.

\section{Referências}

BOCK, Ana Mercês Bahia; FURTADO, Odair; TEIXEIRA, Maria de Lourde Trassi. Psicologias: Uma introdução ao estudo de Psicologia. São Paulo: Saraiva, 2008.

MENEGHETTI, A. Manual de Ontopsicologia. 4. ed. Recanto Maestro: Ontopsicológica Editora Universitária, 2010.

SCHULTZ, Duane P.; SCHULTZ, Sydney Ellen. História da Psicologia Moderna. Tradução de Cintia Naomi Uemura, Marilia de Moura Zanella e Suely Sonoe Murai Cuccio.10.ed. São Paulo: Cengage Learning, 2014. 